\title{
EVALUATION OF TOTAL ANNUAL COSTS OF HEAT EXCHANGER NETWORKS USING MODIFIED PINCH ANALYSIS
}

\author{
Y. Lukman ${ }^{1, *}$, B. Suleiman ${ }^{2}$ and 0. S. Azeez ${ }^{3}$ \\ 1,2,3 Department of Chemical Engineering, Federal University of Technology Minna, Niger State, NiGERIA \\ E-mail addresses:1 yusuflukman55@yahoo.com, 2 bilyaminusuleiman@yahoo.com \\ 3 tosin.azeez@futminna.edu.ng
}

\begin{abstract}
This study presents pinch analysis of some heat exchanger networks (HENs) problems using Hint integration (HINT) software. Three examples reported to have been solved using different approaches by various researchers to obtain the least possible total annual cost (TAC) were solved using the Hint software. In this work, the use of remaining problem analysis (RPA) contained in the heat integration software was used to carry out matching and the general optimization of the networks for minimum TAC for the three problems solved. The results obtained after solving the first problem using RPA based heat integration gave a minimum total annual cost (TAC) of \$237, $510 / y r$. which is the fourth when compared with the lowest solution that shows the minimum TAC of $\$ 235.400 / y$ r. in that example. However, the TAC obtained in solving problem 2 and 3 were $\$ 562,333 / y r$ and $\$ 2.881 \mathrm{M} / \mathrm{yr}$. respectively and they are the least total annual cost obtained when compared with what have been obtained using mathematical programming and non-RPA based Hint software. The overall assessment of the various approaches used to solve these problems when compared with the results obtained in this study shows that HINT software is able to obtain TAC that are within the same range as those obtained using mathematically based technique
\end{abstract}

Keywords: HENs, TAC, HINT, networks, integration.

\section{INTRODUCTION}

Energy integration offers a novel approach that can reduce energy consumption and cost in heat exchanger networks synthesis (HENs)[1]. Energy is needed to drive the heat exchangers system in the process line, where there is a need for the hot streams to decrease in temperature and the cold streams to increase in temperature respectively. This calls for energy integration in form heat exchanger networks (HENs) design. In process integration, the external heating and cooling utilities are reduced to save energy and total annual cost (TAC) [10]. The optimization of chemical processes in industries is being given serious attention because of the need to reduce energy consumption because of the volatile nature of energy cost. This will ultimately lead to reduction in production costs, improved product quality, meeting safety requirements, reduction in energy consumption, and compliance with environmental regulations. The main goal is economics and is stated in various terms such as return, profitability or payback period of an investment [28, 33].

Energy saving is now the driving force for many process industries. Currently, the objective of every process designer is to maximize heat recovery from process to process stream as well as minimizing the utility (energy) requirements. In order to achieve this objective, suitable HENs are needed with the application of process integration techniques [34].

Pinch analysis is one of the tool that has been adopted to accomplish the task of energy minimization. It has been successfully used to solve problems where heating and cooling of process streams are required. The concept of pinch analysis evolved over the years as a result of various research efforts made by a substantial number of researchers. The general progress that has been made over the years to accomplish "energy minimization in HENs and also to develop an optimal heat exchanger network design using pinch analysis" have been presented by various researchers $[14,20,26$. 
In the process of converting raw materials into finished products, different processes are required in chemical process industries. These processes can be represented in different stages and illustrated diagrammatically as an onion diagram [33] as shown in Figure 1. Reactor is the first units required for the reaction of the raw materials; this is the core of the onion. After the reaction, the unreacted feed and the by-products come out of the reactor. The unreacted feed is recycled while the by-products go into the separator in order to be separated to various fractions in their pure form. Therefore, the reactor, separator and the recycle system have to be designed as one unit. In this process, energy is required to drive the reaction, run pumps, and effect the separation and compressors. Therefore, there is a need for cooling the products of the process before collection. This is the basis for energy integration in form of HENs design. Mathematical programming is another technique that has been adopted to accomplish this energy integration technique. The various techniques adopted by various researchers using either the pinch or mathematically based approach for energy integration are contained in $[4,5,8,15]$.

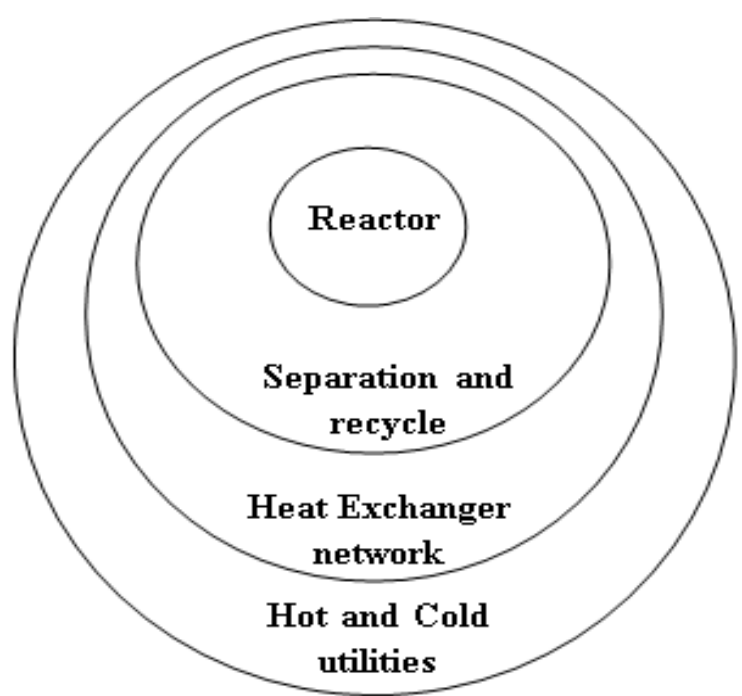

Figure 1: An Onion diagram model illustrating the stages of chemical process design for the conversion of raw materials to products [33].

\subsection{Problem Statement}

In a chemical processing plant, there are a number of hot streams needed to be cooled, and a number of cold streams needed to be heated to their respective target temperatures using utilities such as steam and water. Specified are the heat capacity flowrates, heat transfer coefficients, and supply and target temperatures of each process stream. Available for service are cooling and heating utilities whose costs, heat transfer coefficients, supply temperatures, target temperatures are also given, along with annual operating time, heat exchanger costs and the annual capital cost factor. The task is to synthesis a heat exchanger network that will minimize the utility usage and the cost of the network by optimal exchange of heat between the hot process streams and the cold process streams. The basic aim of HEN is to design a network that will accomplish this task. The effort by various researchers and different approaches adopted to accomplished the aforementioned objective can be seen in [3-12, 16-18, 20-29, 32-36].

The use of pinch analysis and mathematical models for cost reduction has been used to minimize the TAC as reported in literatures $[17,31,36]$. This research seeks to investigate the use of modified pinch analysis approach using heat integration facility called (HINT) to establish the potentials of remaining problem analysis (RPA) to minimize total annual cost for HENs and compare the results with those of other researchers such as pinch technique in [31]; SWS of [36] and DEM of [17].

In [17], a differential evolution method (DEM) was applied to various HENs problems. As implied in [3], the DEM considered stream splitting but did away with the simplifying assumption of isothermal mixing of the split streams of [36]. It was further observed in [3] that the DEM is suitable for optimization problems with continuous variables, whereas HENs problems comprise both continuous variables to quantify the heat duties and temperatures on one hand as well as integer variables that are used for process-process matches or process-utility matches on the other hand. It was observed in [3] that the DEM approach was modified in [17] to accommodate these requirements in HENs.

In order to improve on results obtained from the sequential based pinch techniques, the interval based mixed integer non-linear programming (MINLP) superstructure (IBMS) have been adopted by [15] to optimize the design of heat exchanger networks where the supply and target temperatures of either the hot stream or the cold stream were used to define the intervals of the superstructure to optimise HENs.

The approach adopted in [15] was an extension of the stage-wise superstructure (SWS) presented in [36] for HENs. In [36], MINLP model of a simplified superstructure adopted was based on the assumption of isothermal mixing for the simultaneous optimization of HENs. These assumption of isothermal mixing resulted in linear sets of constraints that made 
the MINLP model robust at the expense of removing a number of structural alternatives.

Consequently [3 - 5] presented the Supply based superstructure (SBS), the supply and target based superstructure (S\&TBS) and the target and supply based superstructure (T\&SBS) to optimize the competing costs in HENs simultaneously. The authors adopted superstructure approaches that were modelled as mixed integer non-linear programming in their work. The techniques all permitted for streams splitting within an interval or stage and also isothermal mixing as done in [36]. Neither the series exchange of split streams nor stream by-passes is allowed by the techniques in a similar manner to [36]. It should be noted that the methods of $[3-5,15,36]$ are all interval based. HINT will now be applied to some of the problems that have been solved by various techniques highlighted.

In HENs synthesis, there is always the need to optimize the operating cost and the capital cost to obtain the optimal total cost. The components of the operating cost are the costs of the hot utilities and the cold utilities while the capital cost is the cost of the heat exchangers. The problem identified with the pinch techniques is the inability to simultaneously optimize these competing interests. It has also been realized that in some cases the design can be complicated and computationally intensive. Therefore, to tackle such enormous and complicated problems in the design of heat exchanger network, one needs to continue to explore all modern techniques especially those offer by computer software application to optimize the cost of HENs. This research seeks to investigate the capability of heat integration (HINT) software to optimize the total annual cost of some existing problems and compare the results with some of the solutions presented by various researchers. HINT software is essentially based on Pinch analysis and some bases of it are presented in [2]. Remaining Problem Analysis (RPA) as presented in [2] has the capacity to evaluate the potential of matches meeting the target area as conceived by the designer.

This present research is based on evaluation of heat exchanger networks based on RPA incorporated in HINT for appropriate matching of streams for the three examples sourced in literature. Remaining Problem Analysis can be regarded as a tool that can be used to study the penalty that will be incurred for every individual match so that the total heat transfer area will not be larger than the target area computed. This gives a more measureable technique that provides values for energy (E), heat transfer area (A), number of units (U) and total annual cost, if a proposed match is accepted [2].

\subsection{Motivation}

The TACs of different HENs problems have been evaluated using the pinch technique and different mathematical techniques, such as non linear programming (NLP) and (MINLP), this study seeks to use optimization form of pinch provided in [13] to evaluate the TAC in HENs and compared with those of other techniques.

\subsection{Data sourced from previous Works}

The stream data in form of supply temperatures, target temperatures, heat capacity flow rates, heat transfer coefficient, hot utility cost, cold utility cost, rate of interest and heat exchanger capital cost data are contained in $[17,31,36]$ and were solved as Examples 1, 2 and 3 respectively in this paper. They are also contained in the work of different set of authors that have solved them previously as highlighted in Tables 4, 5 and 6. The data are shown in Tables 1,2 and 3 respectively.

Table 1: Streams and Cost data for Example 1

\begin{tabular}{cccccc}
\hline $\begin{array}{c}\text { Stream } \\
\text { Name }\end{array}$ & $\begin{array}{c}\mathrm{T}^{\mathrm{s}} \\
\left({ }^{\circ} \mathrm{C}\right)\end{array}$ & $\mathrm{T}^{\mathrm{t}}\left({ }^{\circ} \mathrm{C}\right)$ & $\begin{array}{c}\mathrm{F}(\mathrm{kW} \\
\left.{ }^{\circ} \mathrm{C}^{-1}\right)\end{array}$ & $\begin{array}{c}\mathrm{H}(\mathrm{kW} \\
\left.\mathrm{m}^{-2} \mathrm{C}^{-2}\right)\end{array}$ & $\begin{array}{c}\text { Cost } \\
(\$)\end{array}$ \\
\hline $\mathrm{H} 1$ & 175 & 45 & 10 & 0.2 & - \\
$\mathrm{H} 2$ & 125 & 65 & 40 & 0.2 & - \\
$\mathrm{C} 1$ & 20 & 155 & 20 & 0.2 & - \\
$\mathrm{C} 2$ & 40 & 112 & 15 & 0.2 & - \\
$\mathrm{S} 1$ & 180 & 179 & - & 0.2 & 120 \\
$\mathrm{~W} 1$ & 15 & 25 & - & 0.2 & 10 \\
\hline
\end{tabular}

Annualization factor $=0.322$, utility costs in $\$ \mathrm{~kW}^{-1} \mathrm{yr}^{-1}$, Payback period 12yr and Capital cost $(\$)=30,000+$ $750 * A^{0.81}$. $A$ is the Area of heat transfer in all exchangers $\left(\mathrm{m}^{2}\right)$

Table 2: Streams and Cost Data for Example2

\begin{tabular}{lcccc}
\hline $\begin{array}{l}\text { Strea } \\
\mathrm{m}\end{array}$ & $\begin{array}{c}\mathrm{Ts} \\
(\mathrm{K})\end{array}$ & $\begin{array}{c}\mathrm{Tt} \\
(\mathrm{K})\end{array}$ & $\mathrm{F}\left(\mathrm{kW} \mathrm{K}^{-1}\right)$ & Cost $\left(\$ \mathrm{~kW}^{-1}\right.$ year-1 \\
\hline $\mathrm{H} 1$ & 500 & 320 & 6 & - \\
$\mathrm{H} 2$ & 480 & 380 & 4 & - \\
$\mathrm{H} 3$ & 460 & 360 & 6 & - \\
$\mathrm{H} 4$ & 380 & 360 & 20 & - \\
$\mathrm{H} 5$ & 380 & 320 & 12 & - \\
$\mathrm{C} 1$ & 290 & 660 & 18 & - \\
S1 & 700 & 700 & - & 140 \\
W1 & 300 & 320 & - & 10 \\
\hline
\end{tabular}

$\mathrm{U}$ is the $1 \mathrm{~kW} \mathrm{~m}^{-2} \mathrm{~K}^{-1}$ for all matches, heat exchanger annual cost $=\$ 1200 * A^{0.6}$ for all exchangers. 
Table 3: Stream and Cost Data for Example3

\begin{tabular}{lcccc}
\hline Stream & $\mathrm{Ts}(\mathrm{K})$ & $\mathrm{Tt}(\mathrm{K})$ & $\mathrm{F}\left(\mathrm{kW} \mathrm{K}^{-1}\right)$ & $\mathrm{h}\left(\mathrm{kW} \mathrm{m}^{-2} \mathrm{~K}^{-1}\right)$ \\
\hline $\mathrm{H} 1$ & 600.15 & 313.15 & 100 & 0.50 \\
$\mathrm{H} 2$ & 493.15 & 433.15 & 160 & 0.40 \\
$\mathrm{H} 3$ & 493.15 & 333.15 & 60 & 0.14 \\
$\mathrm{H} 4$ & 433.15 & 318.15 & 400 & 0.30 \\
$\mathrm{C} 1$ & 373.15 & 573.15 & 100 & 0.35 \\
$\mathrm{C} 2$ & 308.15 & 437.15 & 70 & 0.70 \\
C3 & 358.15 & 411.15 & 350 & 0.50 \\
C4 & 333.15 & 443.15 & 60 & 0.14 \\
C5 & 413.15 & 573.15 & 200 & 0.60 \\
Hot oil & 603.15 & 523.15 & - & 0.50 \\
CW & 288.15 & 303.15 & - & 0.50 \\
\hline
\end{tabular}

Plant lifetime $=5$ years; rate of interest $=0 \%$; exchanger cost $=\$ 10,000+350 * \mathrm{~A}$, cost of hot oil $=60$ $(\$ /$ year $) / \mathrm{kW}$; cost of cooling water $(\mathrm{CW})=6$ (\$/year)/kW.

\section{METHODOLOGY}

The methodology of this research work consist of data source from literature, data input and simulation in HINT environment; Optimization of $\Delta \mathrm{T}_{\mathrm{min}}$, optimum, network design and finally comparison of the results obtained in this research with those of previous researchers as summarized in Figure 2.

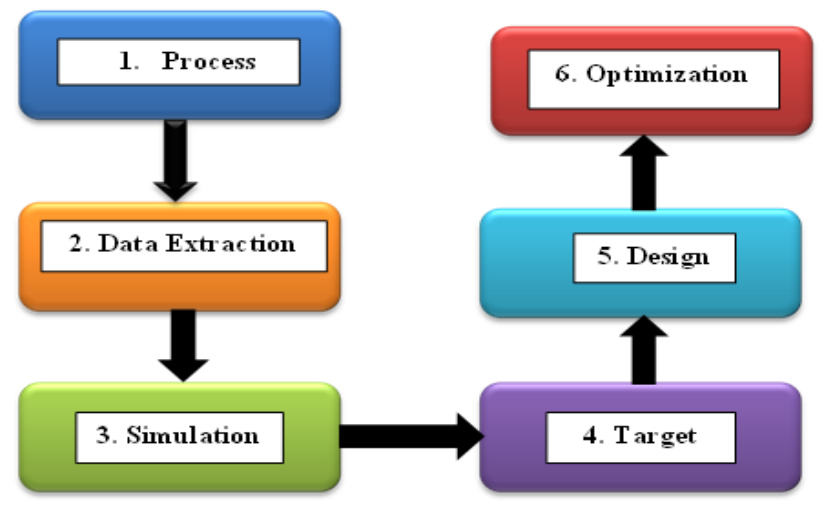

Figure 2 Phases involved in Pinch analysis

\subsection{Data input and simulation in HINT}

The data obtained were used as input in the simulation environment and processed by the package to include the following; adds stream dialogue box, selection of $\mathrm{T} \Delta_{\min }$, generates grid diagram, generation of composite and grand composite curves among other features.

\subsection{Design of Grid Diagram in HINT}

The matching and splitting of the streams were carried out on the grid through the following procedures: the matching was carried out using the MCp rule and other feasibility criteria obtainable in pinch technology [31]. Equation 1 is the basic equation for quantifying the energy available/required in each of the streams and the utility. All possible matching was achieved using the basic pinch rules such as those in[22].

$$
Q=M C p \Delta T
$$

In (1), $Q$ is the heat transfer $(\mathrm{kW}), \mathrm{MCp}$ is the heat capacity flow rate $(\mathrm{kW} / \mathrm{K})$ and $\Delta \mathrm{T}$ is the temperature difference (K).

The matching which has various options above and below the pinch was done in HINT environment using remaining problem analysis. This checks for the best possible matches for total heat flow areas that meet the area target. RPA analysis definitely leads to improved energy and capital since it gives networks that meet the target.. After the RPA based on target area, the energy target, minimum number of units and cost target was evaluated and displayed for the optimal minimal area selected [2].

\subsection{Optimization of $\Delta \mathrm{T}_{\min }$ in HINT}

The $\Delta \mathrm{T}_{\min }$ for energy targets, number of heat exchanger and area target were selected for optimization in the diagram menu $\Delta \mathrm{T}_{\min }$ analysis. The optimal $\Delta T$ min can be identified on the cost target versus $\Delta \mathrm{T}_{\text {min }}$ graphs plotted in HINT. The result of the total annual cost was optimized and comparison with the literature results shown in Table 4, 5 and 6. HINT is essentially a pinch based package that utilizes the heuristics and cost data available in literatures [6], [31] and [33].

\section{RESULTS AND DISCUSSIONS}

In all the three examples presented, RPA based HINT package approach was used to carry out simultaneous approach of heat exchanger networks with objective function of minimum total annual cost optimization.

\subsection{Example 1}

This is a problem of two hot streams, two cold streams with one hot and one cold utility taken from [31].The problem specifications are in Table 1.

This example features equal heat transfer coefficients for all streams and it has been solved by different set of researchers. The author in [31] solved this problem using the SWS of [36] to obtain a TAC of $\$ 235,400 / \mathrm{yr}$ while in [15], it was solved using both the hot based and the cold based technique of the IBMS. The hot based IBMS gave a TAC of $\$ 237,800 / \mathrm{yr}$ while the cold based IBMS gave a TAC of $\$ 239,332 / \mathrm{yr}$. Two intervals were used for the SWS while the IBMS have five minimum number of heat exchanger in its network. 
The TAC obtained in the present study is $\$ 237,510 / \mathrm{yr}$ with 6 heat exchangers.

Table 4 presents the comparison of the result obtained in this study with those of other researchers. The method of SWS as presented by [31] obtains the lowest TAC, while the T\&SBS features the highest. The entire methods feature the same number of units, the SWS has two intervals for this problem while all other techniques have either five or six intervals. All the TACs obtained by different researchers, especially the lowest four, are fairly close to one another. The SWS obtains the lowest TAC. All the solutions produced splits streams but the RPA based solution explored in this research has no split stream.

The comparison of the results obtained in this study with those of previous researchers is shown in Table 4 and the grid diagram of the present study presented in Figure 2. The TAC obtained in this research is $\$ 237,510 / y r$ which is higher than the SWS technique but lower than the IBMS and the S\&TBS solutions.This shows that the pinch technique is able to obtain a TAC that is comparable with those of mathematically based techniques. The absence of split streams in the solution obtained using RPA techniques indicates lower cost in the piping system.

\subsection{Example 2}

This problem was previously reported in Magnet user Manual and [36] used it for SWS analysis of cases requiring stream splits. The problem consists of five hot streams, one cold stream, one hot utility (steam) and one cold utility (cooling water). The stream and cost data are shown in Table 2 and Figure 3 shows the network design of the structure obtained in this work. The problem was analysed by many researchers with expectation of possibly having as much number of splits as possible as demonstrated by the results that are contained in Table 5. Previous attempt to minimize the total annual cost was carried out by many researchers $[3-5,15,36]$. The application of RPA based HINT technique to evaluate this problem resulted in two stream splits similar to results obtained in a previous work [18]. The number of units obtained in this research is 8 and the detail comparison with those of previous workers is shown in Table 5. The approach used in this work resulted in the least total annual cost of $\$ 562,331 / \mathrm{yr}$. Comparison has shown that the total annual cost achieved by the RPA technique is comparable with results achieved by previous researchers.

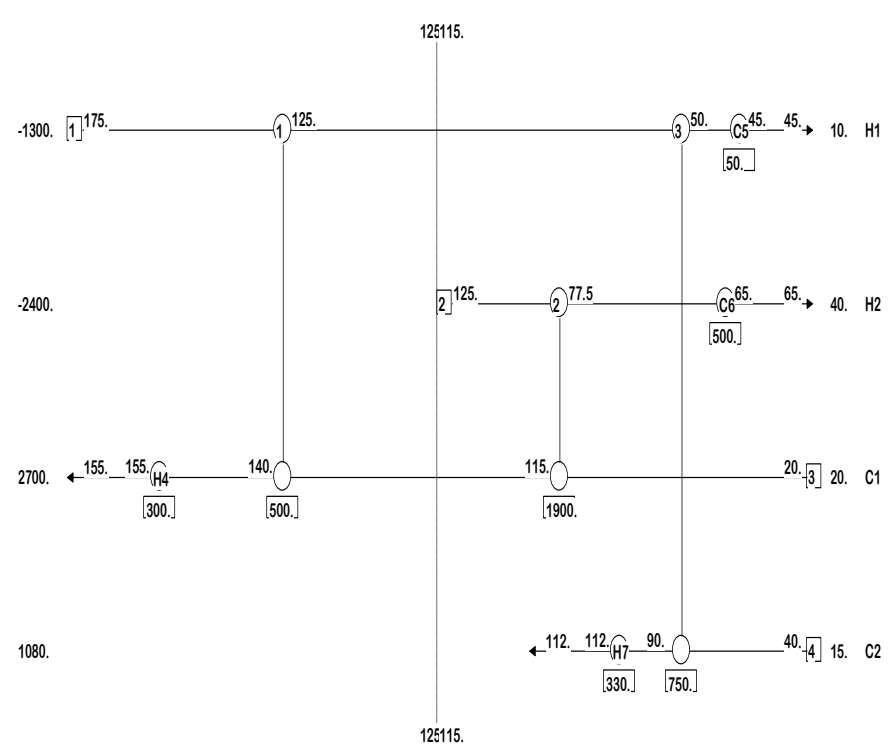

Fig.2: Grid Diagram for Example 1

Table 4: Comparison of Results for Example 1

\begin{tabular}{lccccc}
\hline Method & $\begin{array}{c}\text { Stream } \\
\text { splits }\end{array}$ & $\begin{array}{c}\text { No of } \\
\text { interval }\end{array}$ & $\begin{array}{c}\text { No. } \\
\text { of } \\
\text { units }\end{array}$ & $\begin{array}{c}\text { TAC } \\
(\$ / y r .)\end{array}$ & $\begin{array}{l}\text { Diff. } \\
(\%)\end{array}$ \\
\hline [3] & 2 & 6 & 6 & 240,253 & 2.062 \\
$\begin{array}{l}\text { Cold Stream } \\
\text { based in [15] }\end{array}$ & 3 & 6 & 6 & 239,332 & 1.670 \\
Hot Stream & 2 & 6 & 6 & 237,800 & 1.020 \\
based in [15] & 2 & 7 & 7 & 237,510 & 0.896 \\
Present study & 0 & 6 & 6 & 235,931 & 0.226 \\
[4] & 2 & 6 & 6 & 235,781 & 0.162 \\
[3] & 2 & 6 & 6 & 235,781 & 0.162 \\
[36] & 2 & 6 & 6 & 235.400 & 0.00 \\
\hline 31$]$ & 2 & & & &
\end{tabular}

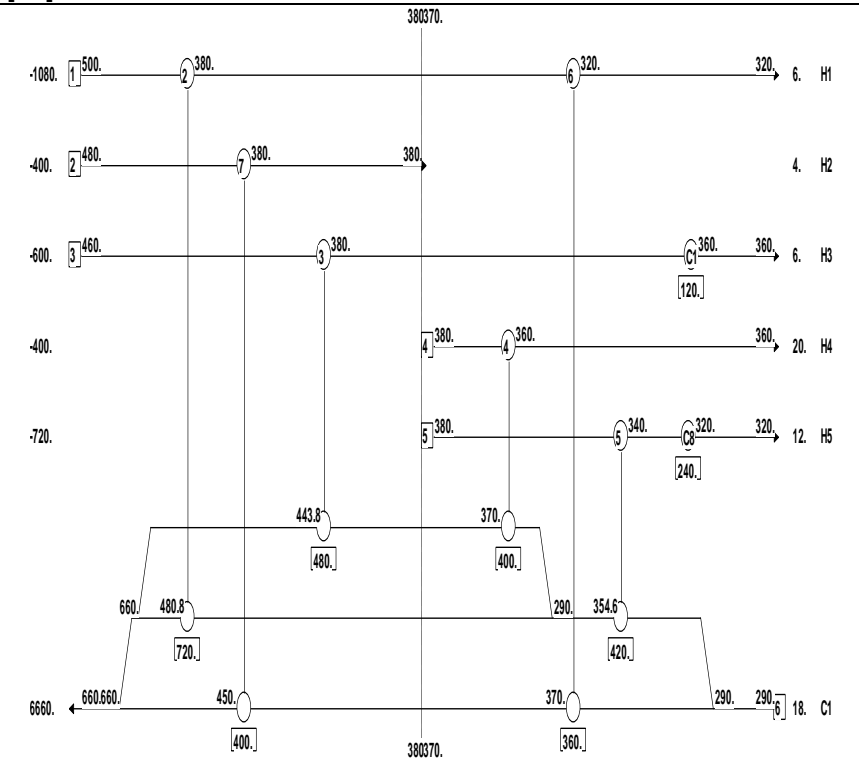

Fig.3: Grid Diagram for Example 2

\subsection{Example 3}

This example is an aromatic plant problem reported in previous works [17 - 19] that attempted to determine the optimal TAC of the network. The problem consists 
of four hot streams and five cold streams having significantly different heat transfer coefficients as shown in Table 3 and the grid diagram of the solution obtained in this study shown in Figure 4. The result obtained using HINT software shows that two (2) stream splits and twelve (12) number of units was obtained. Total annual cost of $\$ 2.881$ million per/year was obtained and is the least when compared with other total minimum annual cost reported in literature as shown in Table 6. The minimal number of splits signifies reduction in the cost of piping. Sequential match reduction approach of [30] gives the next lowest cost of $\$ M 2,905 / y r$. The highest cost is that obtained by the DEM of [17] with a cost of $\mathrm{M} \$ 3.146 / \mathrm{yr}$. and percentage difference of $9.19 \%$ higher. The results obtained shows that the HINT is a robust tool capable of identifying optimal network from alternatives available.

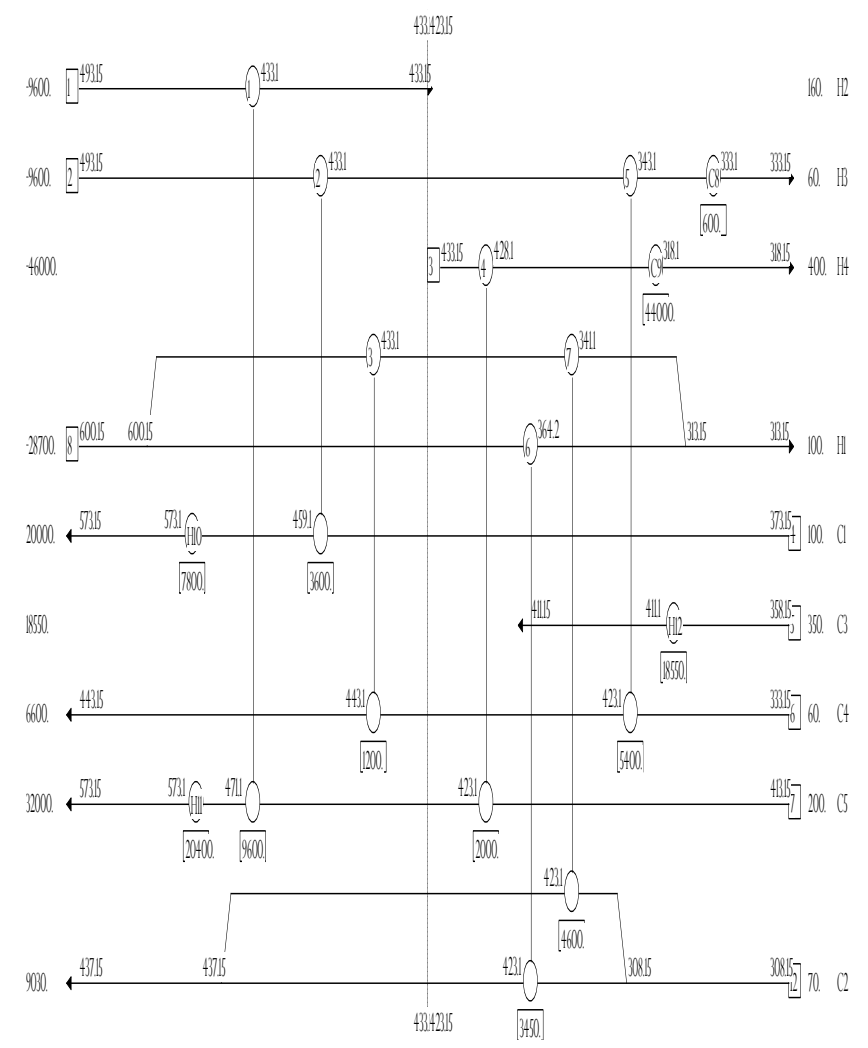

Fig. 4: Grid Diagram for Example 3

Table 5: Comparison of Results for Example 2

\begin{tabular}{lccccc}
\hline Method & $\begin{array}{c}\text { No. of } \\
\text { intervals }\end{array}$ & $\begin{array}{c}\text { Stream } \\
\text { splits }\end{array}$ & $\begin{array}{c}\text { No. of } \\
\text { units }\end{array}$ & $\begin{array}{c}\text { TAC } \\
(\$ / y e a r)\end{array}$ & $\begin{array}{c}\text { Diff. } \\
(\%)\end{array}$ \\
\hline Cold stream & 3 & 1 & 7 & 595,064 & 5.821 \\
based in [15] & 6 & 1 & 7 & 581,954 & 3.490 \\
[4] & 7 & 1 & 7 & 581,942 & 3.487 \\
Hot stream & 7 & 1 & 7 & 581,942 & 3.487 \\
based in [15] & 7 & 1 & 8 & 580,023 & 3.146 \\
[3] & 6 & 1 & 10 & 577,602 & 2.716 \\
[5] & 7 & 1 & 7 & 576,640 & 2.545 \\
[3] & 5 & 2 & 9 & 573,205 & 1.934 \\
[36] & - & 2 & 8 & 562,331 & 0.00 \\
[18] & - & & & & \\
Present & & & & &
\end{tabular}

\section{CONCLUSION}

The following conclusion may be drawn from the results of the analysis

- Comparison of results in the three examples solved shows that the RPA technique in pinch is capable of returning TAC that is comparable with those retuned by mathematically based techniques.

- Comparison of results for the three examples solved also show that pinch technique can sometimes obtain the lower TAC than the mathematical technique in heat exchanger networks.

\section{REFERENCES}

[1] Ahmad, S.. Heat Exchanger Networks; Cost tradeoffs in Energy and Capital, PhD Thesis, UMIST 1985.

[2] A'ngel, M. and Fidel, A. M. The use of HINT, Education for Chemical Engineering Retrieved from $h$ ttp//www.eng.auth.gr/ chemtech/foititika/energeri a/mar08_martin_hint\%20program.pdf, 2008.

[3] Azeez, O. S., Isafiade, A. J and Fraser, D. M.. Supply and Target Based Superstructure of Heat and Mass Exchanger Networks, Chemical Engineering Res. Design 90, 266-287. 2012.

[4] Azeez, O. S., Isafiade, A. J and Fraser, D.M. Supply and Target Based Superstructure of Heat and Mass Exchanger Networks, International Conference University of Technology Malaysia IEEEC, Conference Publication 1-6. 2011.

[5] Azeez, O. S., Isafiade, A. J and Fraser, D. M. Supply Based Superstructure of Heat and Mass Exchanger Network, Chemical Engineering Res. Design 56, 184201, 2013.

[6] Ahmad, S. and Smith, R. Targets and design for minimum number of shells in heat exchanger networks, Trans IChemE, 67:481 - 494. 1989.

[7] Ciric, A. R. and Floudas, C .A. Heat Exchanger Network Synthesis without Decomposition, Chemical Engineering, 15, 385-396. 1991. 
[8] Dagde, K. K. and Piagbo, B. K. Using Simulation Modelling to Improve the Performance of Chemical Engineering Processes, International Journal of Pure and Applied Sciences and Technology, 12(1), 39-48, 2012.

[9] Daichendt, M. M. and Grossmann, I. E.. Preliminary Screening Procedure for the MINLP Synthesis of Process Systems 11 Heat exchanger networks, Computer and Chemical Engineering.18-679.1994.

[10] Floudas, C. A. Nonlinear and Mixed Integer Optimization: Fundamentals and Application ( $2^{\text {nd }}$ ed.).Oxford University Press, New York, USA, 78218. 1995.

[11] Hallale, N. and Fraser, D. M.. Capital and Total Cost Targets for Mass Exchange Networks, Part 2: Detailed Capital Cost Models, Computer and Chemical Engineering, 23, 1681 - 1699. 2000.

[12] Hindmarsh, E. and Linnhoff, B.. Pinch Design Method of Heat Exchanger Network, Chemical Engineering Science, 38(5), 745-757. 1983.

[13] HINT, Department of Chemical Engineering and Environment Technology University of Valladolid Spain. Retrieved from http//www.iq.uva.es/integ/hint.zip/ 2008.

[14] Hohmann, E. C.. Optimum Networks for Heat Exchanger. Ph. D. Thesis Submitted to University of Southern California, U.S.A. 1971.

[15] Isafiade, A. J. Interval Based MINLP Superstructure Syntheses Heat and Mass Exchange Networks, PhD Thesis, Submitted to Department of Chemical Engineering, University of Cape Town, 23-40. 2008.

[16] Joe, M. P., Medardo, S., and Arturo, J.. Synthesis of Heat Exchanger Networks with Optimal Placement of Multiple Utilities, Ind. Eng. Chem. Res., 49, 28492856. 2010.

[17] Krishna, M. Y. and Murty, C. V. S.. Synthesis of CostOptimal Heat Exchanger Networks Using Differential Evolution, Computer and Chemical Engineering32, 1861-1876. 2007.

[18] Lewin, D. R.. A Generalized Method for HEN Synthesis Using Stochastic Optimization-II. The Synthesis of Cost-Optimal Networks, Computer and Chemical Engineering, 22(10), 1387-1405. 1998.

[19] Linnhoff, B. \& Ahmad, S.. Cost optimum heat exchanger networks (Part I). Comp. \& Chem. Eng., 14(7): 729-750.1990.

[20] Linnhoff, B. and Flower, J. R.. Synthesis of Heat Exchanger Networks, American Institute of Chemical Engineering Journal, 24(4), 633-642. 1978.

[21] Linnhoff, B. Thermodynamic Analysis in the Design of Process Networks, Ph.D. Thesis Submitted to University of Leeds, U. K. 1979.

[22] Linnhoff, B. and Kemp, I. C.. Pinch Analysis and Process Integration, a User Guide on Process Integration for the Efficient Use of Energy (2 ${ }^{\text {nd }}$ ed.). Oxford University Press, New York, USA. 372-711, 2007.
[23] Linnhoff, B and Hindmarch, E. Pinch Design Method for Heat Exchanger Networks, Chemical Engineering Science,38(5), 745-763. 1983.

[24] Linnhoff, B. New Concept of Thermodynamics for Better Chemical Process Design, Royal Society Esso Energy Award Lecture, Chemical Research and Development. 61, 207-223. 1983.

[25] Linnhoff, B. and Parker, S.. Heat Exchanger Network with Process Modification, International Chemical Engineering Annual Research Meeting, Bath UK, 120142. 1984

[26] Linnhoff, B., Townsend, D., Boland, G.F. Hewitt, B. E. A. Thomas, A.R. Guy and Marsland, R.H.. User Guide on Process Integration for the Efficient Use of Energy, Institute of Chemical Engineering, U.K, 1-18. 1982.

[27] Linnhoff, B. and Vredeveld, D. R. Pinch Technology has come of Age. Chemical Engineering Progress, 3340. 1984 .

[28] Lukman, Y., Suleiman, B., Azeez, S. O. Analysis of Heat Exchanger Networks for Minimum Total Annual Cost Using Pinch Analysis, International Engineering Conference, Federal University of Technology Minna, Nigeria, 1-7. 2015.

[29] Pinch Technology: Basics for Beginners, Retrieved fro $\mathrm{m} \mathrm{htt://www.cheresources.com/pinchtech2.shtml/}$

[30] Pettersson, F. Synthesis of Large-Scale Heat Exchanger Networks Using a Sequential Match Reduction Approach. Computer and Chemical Engineering, 29(5), 993-1007. 2005.

[31] Shenoy, U. V.. Heat Exchanger Network Synthesis for Process Optimisation, Energy and Resource Analysis. Gulf publishing Company, Houston Texas. 121-127. 1995.

[32] Shenoy, U. V., Sinha, A. and Bandyopadhyay, S.. Multiple Utilities Targeting for Heat Exchanger Networks. Institute of Chemical Engineering, 76, 259-272. 1998.

[33] Smith, R., Chemical Process Design and Integration ( $2^{\text {nd }}$ ed.). John Wiley and Sons, Ltd. England. 115-119, 2005.

[34] Salomeh, C., Dargehi, R., Mahdayi, A. Modification of Preheating Heat Exchanger Network in Crude Distillation Unit of Arak Refinery Base on Pinch sama Technology, WCECS 2008.

[35] Sorsak, A. and Kravanja, Z. Simultaneous MINLP Synthesis of Heat Exchanger Networks Comprising Different Exchanger Type, Computer and Engineering, 24(4), 599-615. 2002.

[36] Yee, T.F. and Grossmann, I. E..Simultaneous Optimization Models for Heat Integration- II Heat Exchanger Network Synthesis, Computer and Chemical Engineering, 14(10), 1165 - 1184. (1990).

[37] Zhu, X.X., O'Neill, B.K., J.R., \& Wood, R. M. A method for the automated heat exchanger synthesis using block decomposition and non-linear optimization. Chem. Eng Res \& Des, Part A, 73(11), 919-930, 1990. 